\title{
A IMPORTÂNCIA DA PRESERVAÇÃO E INTERVENÇÃO NO PATRIMÔNIO HISTÓRICO INDUSTRIAL NA CIDADE DE MIRANDÓPOLIS-SP: ESTAÇÃO FERROVIÁRIA
}

Willian da Silva, Yeda Ruiz Maria

Universidade do Oeste Paulista - UNOESTE, Curso de Arquitetura e Urbanismo, Presidente Prudente, SP. E_mail: will.silvaa1@hotmail.com, yeda rm@hotmail.com.

\section{RESUMO}

O patrimônio histórico industrial corresponde às expressões, materiais ou imateriais, que foram produzidas para atender a demanda do processo industrial. Com este setor, surgiram significativos serviços e construções que mudaram o modo de vida da população, tendo como exemplo o próprio setor ferroviário. O objetivo deste estudo foi defender a preservação e intervenção no patrimônio histórico industrial que encontra-se abandonado, que corresponde à estação ferroviária de Mirandópolis-SP. A metodologia constou com levantamentos in loco utilizando levantamentos qualitativos do edifício.

Palavras-chave: Patrimônio Histórico, Patrimônio Industrial, Intervenção, Ferrovia, Mirandopolis-SP.

THE IMPORTANCE OF PRESERVATION AND INTERVENTION IN HISTORICAL INDUSTRIAL HERITAGE IN THE CITY OF MIRANDÓPOLIS-SP: RAILWAY STATION

\begin{abstract}
The historical industrial patrimony corresponds to the expressions, material or immaterial, that were produced to meet the demand of the industrial process. With this sector, significant services and constructions have emerged that have changed the way of life of the population, taking as an example the railway sector itself. The objective of this study was to defend the preservation and intervention in the historical industrial patrimony that is abandoned, which corresponds to the railway station of Mirandópolis-SP. The methodology consisted of on-site surveys using qualitative surveys of the building.
\end{abstract}

Keywords: Historical Heritage, Industrial Patrimony, Intervention, Railroad, Mirandopolis-SP. 


\section{INTRODUÇÃO}

Segundo Kuhl (s/a), o interesse pela preservação do patrimônio industrial é recente e deve ser visto como uma ampliação no acervo de bens culturais, porém, até hoje, muitas vezes a preservação tem início tardio e leva a obra a danos irreversíveis. É necessário que os bens culturais sejam submetidos à preservação, restauração e intervenção, para exercerem nova função social, e assim, servir à população e ser tão importante quanto foi no passado.

A área de estudo apresentada corresponde à estação ferroviária na cidade de Mirandópolis-SP. A estação surgiu na primeira metade do século XX para atender a demanda do transporte de pessoas e cargas durante o período industrial. A estação foi desativada após a substituição deste setor pela rapidez do transporte rodoviário e desde então encontra-se em estado de abandono, sem nunca ter passado por intervenções. $O$ objetivo foi registrar os levantamentos realizados e apresenta-los conciliados a uma revisão bibliográfica sobre a importância da preservação e intervenção nos bens patrimoniais. A metodologia constou através de levantamentos in loco com o intuito de vivenciar a situação atual do espaço, analisando os dados de forma qualitativa para encontrar as melhores alternativas para intervir no espaço.

\section{METODOLOGIA}

A metodologia deste trabalho aconteceu a partir de levantamentos in loco com analise qualitativa da situação atual da edificação e seus componentes.

\section{RESULTADOS}

Por ser uma cidade que surgiu à partir da implantação dos equipamentos ferroviários, a estação ferroviária de Mirandópolis -SP pode ser considerada o equipamento urbano indutor da fundação do município, assim, podendo ser classificada como uma cidade ferroviária.

A implantação dos equipamentos ferroviários surgiu na década de 30 , a partir da extensão da malha ferroviária de Valparaíso, conectando-se a importantes cidades da região, como Andradina e Araçatuba, e destinando-se ao transporte de cargas e passageiros do estado de São Paulo até o estado do Mato Grosso do Sul. (FARIA, s/a)

No período em que a estação ferroviária foi construída, o setor industrial estava a todo vapor, sendo este, outro responsável por atrair moradores para perto da sua zona de trabalho. No caso de Mirandópolis -SP, a ferrovia também foi a responsável por atrair as primeiras indústrias, pois assim era possível ter o local de produção próximo ao local de importação e exportação. (FALLEIROS, s/a).

A primeira metade do século $X X$ foi marcada pelo desenvolvimento dos setores industriais, produzindo edificações com características da arquitetura industrial. Atualmente, o que temos como preexistência são os resquícios de um setor que influenciou na economia nacional e em questões de educação, cultura e lazer da população.

Para entender ainda mais sobre a arquitetura industrial produzida na década de 30 , foi realizado um estudo da preexistência à partir de levantamentos in loco, que analisam a edificação em relação ao seu estado de preservação, suas dimensões, características arquitetônicas industriais e todos os aspectos necessários para a compreensão de sua importância história.

A estação ferroviária (FIGURA 1) é o principal edifício do complexo ferroviário e é datado da primeira metade do século $X X$, onde funcionava como espaço para embarque e desembarque de passageiros, depósito para importações e exportações de mercadorias, e 
também ações administrativas, como a venda de passagens. Não se sabe até quando este serviço funcionou no município. O que se sabe é que ele funcionou até ser substituído pela rapidez do transporte rodoviário, sendo que depois deste acontecimento, a estação manteve-se inativa até os dias atuais, não exercendo nenhuma outra função. A seguir, serão apresentados levantamentos do estado atual da edificação, que consistem em levantamentos fotográficos, análises qualitativas, e levantamentos dimensionais, retratando a situação atual da obra.

Figura 1. Implantação da estação ferroviária

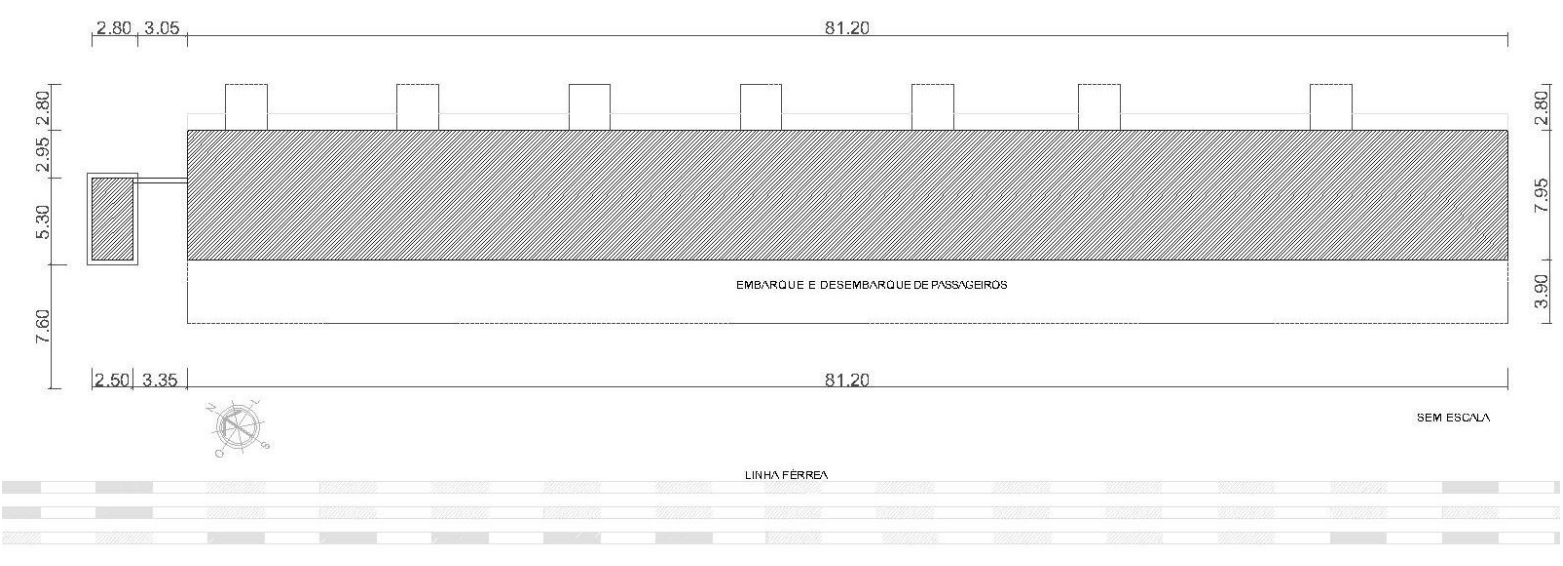

Fonte: Arquivo Pessoal, 2017

Ao lado esquerdo de quem olha da área de embarque e desembarque da estação ferroviária, encontra-se um túnel de acesso entre as Av. São Paulo e Av. Rafael Pereira, vencendo um desnível aproximado de três (3) metros através de escadas. Este anexo funciona como um acesso vertical que vence o desnível entre a Av. Rafael Pereira e o pátio da estação.

Quanto às características construtivas da estação, a fachada estação ferroviária segue o estilo industrial, com planta retangular, funcional e simétrica, como mostra a FIGURA 2.

Figura 2. Fachada da Av. São Paulo

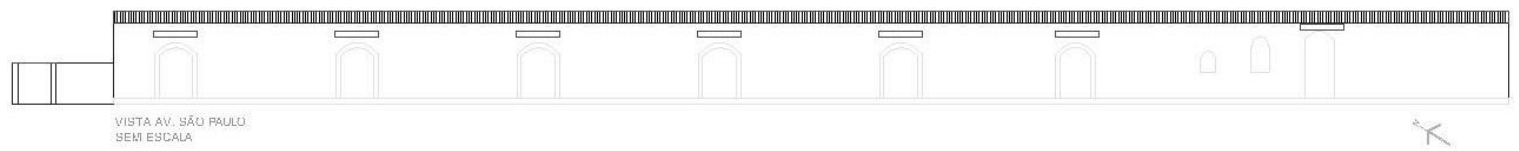

Fonte: Arquivo Pessoal, 2017

A arquitetura industrial consiste na arquitetura de edifícios de maquinaria, oficinas, fábricas, minas e locais de processamento e de refinação, entrepostos e armazéns, centros de produção, transmissão e utilização de energia, meios de transporte e todas as suas estruturas e infraestruturas, assim como os locais onde se desenvolveram atividades sociais relacionadas com a indústria, tais como habitações, locais de culto ou de educação. (KUHL, 2010).

Este estilo arquitetônico pertencente à estação ferroviária seguia as mesmas características construtivas dos demais equipamentos ferroviários do Brasil: forma simétrica, cobertura simples de duas águas, lado maior paralelo à linha férrea e espaços internos flexíveis, que funcionavam como depósito. Essa arquitetura remete diretamente ao passado, 
relembrando o estilo industrial e sua importância histórica para a época, quando a ferrovia era vista pela população como um grande avanço tecnológico.

A imagem a seguir mostra a comparação do projeto da estação ferroviária com a situação atual do edifício. Até o momento não houve intervenção humana que descaracterizasse a edificação, porém, os elementos encontram-se em estado de abandono devido à falta de manutenção e por isso sofrem danos com as intempéries do tempo.

Figura 3. Fachada principal da estação.

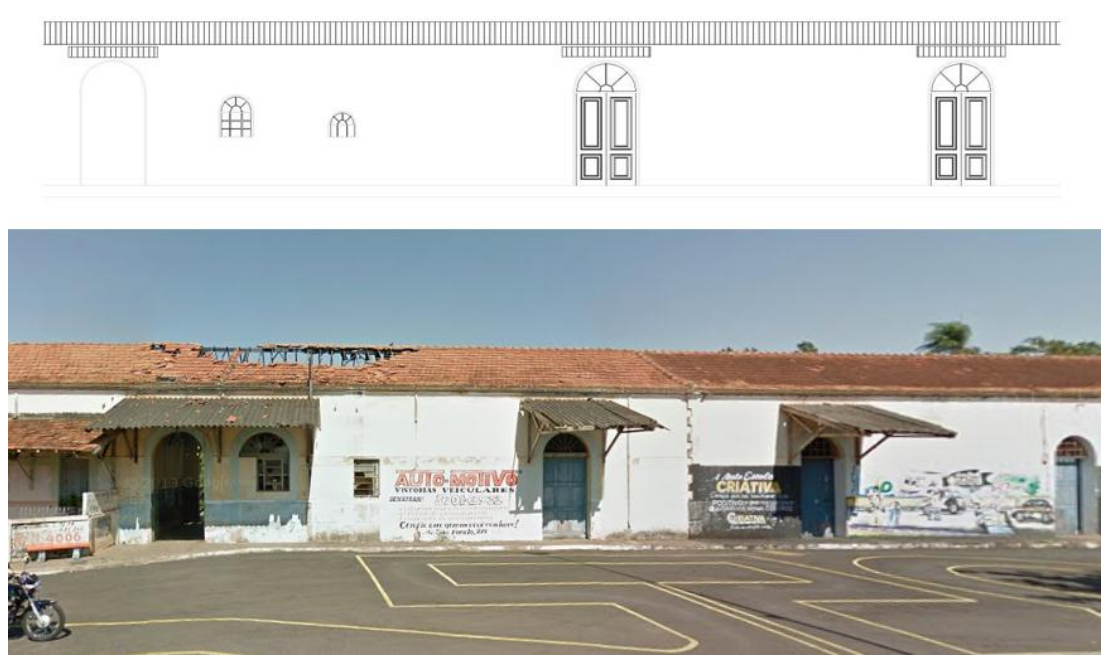

Fonte: Arquivo Pessoal, 2017

Atualmente, a estação ferroviária mantém a configuração original dos ambientes como consta na planta baixa. O programa de necessidades da estação ferroviária é composto por: hall de entrada, uma (1) bilheteria, dois (2) depósitos, um (1) sanitário público, uma (1) copa para funcionários, um (1) sanitário para funcionários e uma (1) plataforma de embarque e desembarque.

Figura 4. Planta baixa da estação.

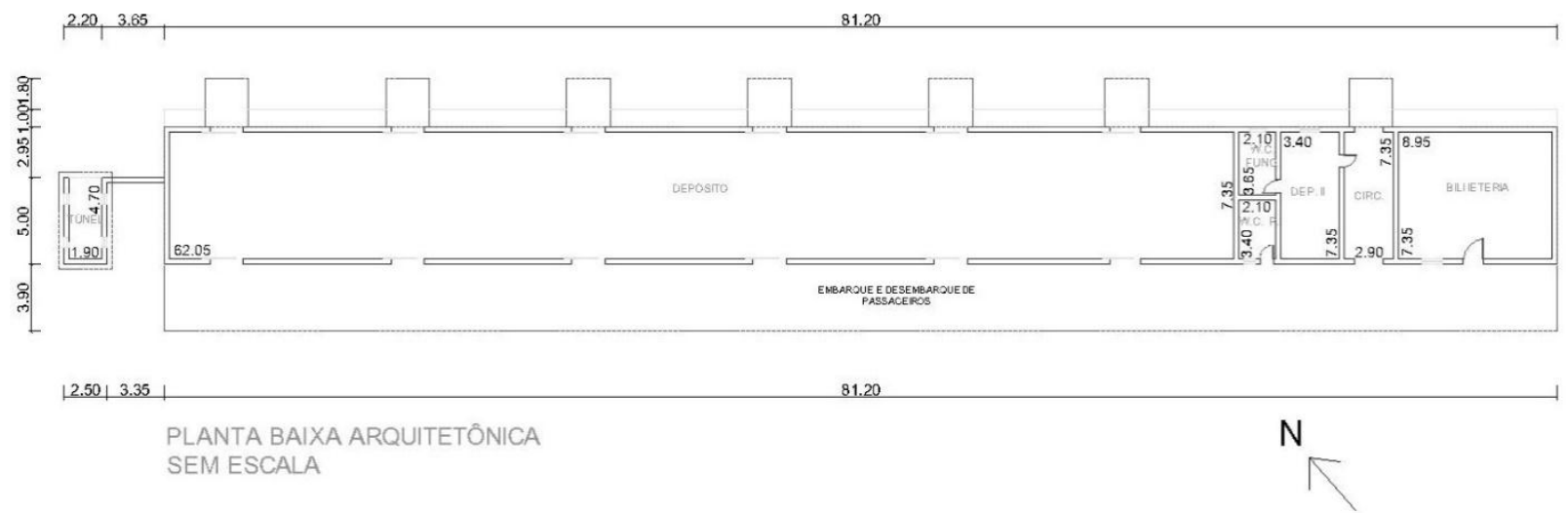

Fonte: Arquivo Pessoal, 2017

Os acessos ao edifício acontecem pelos espaço de circulação entre a bilheteria e o depósito, que funciona como um hall de entrada para a plataforma de embarque e desembarque e dá acesso aos demais ambientes, tais como o depósito, a bilheteria e ao sanitário público. Também foi possível constatar que os ambientes da estação não possuem 
ligação entre si, como por exemplo, não é possível o acesso ao depósito à partir da copa, ou então acessar o depósito através da bilheteria ou dos demais ambientes administrativos. Os ambientes são isolados, dificultando a circulação e acessos pela parte interior do edifício. Assim, maioria dos ambientes só podem ser acessados pela plataforma de embarque e desembarque ou pelo pátio da estação (setorizado com a cor amarela na imagem abaixo), localizado na Av. São Paulo (figura 5).

Figura 5. Fluxograma e setorização.

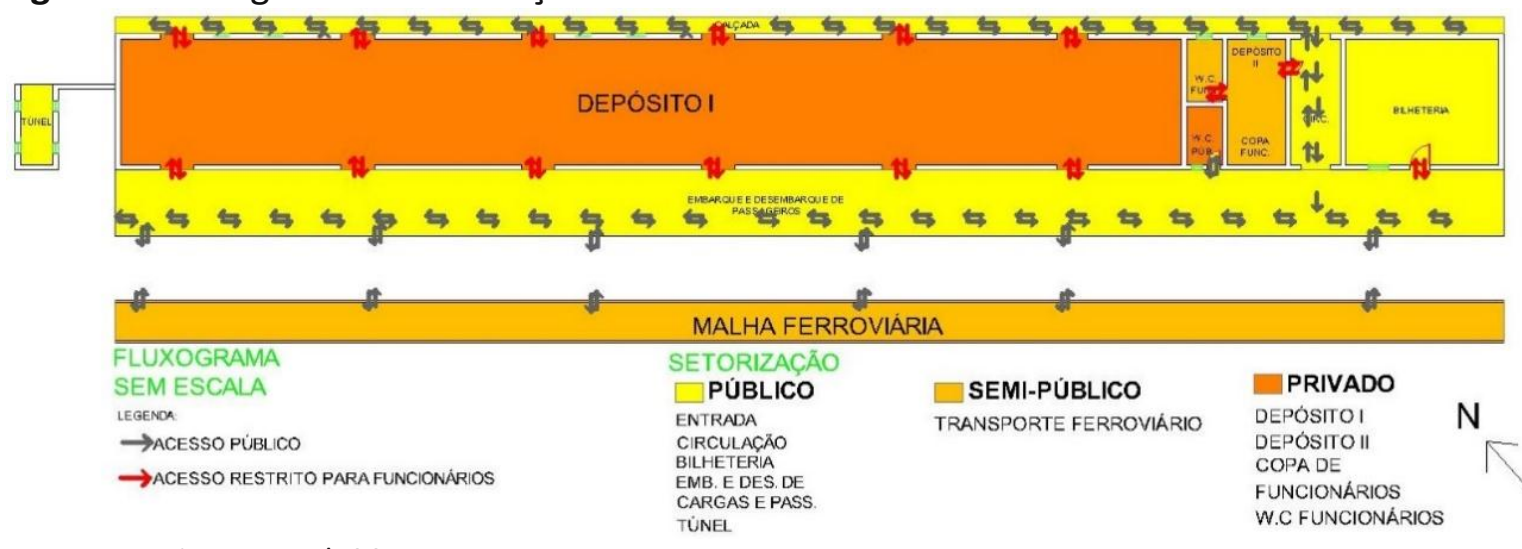

Fonte: Arquivo Pessoal, 2017

Desde que foi desativada, a estação ferroviária não passou por manutenção, exceto a linha férrea, que ainda contínua ativa para o transporte de cargas. Essa falta de manutenção e zelo pelo patrimônio levou ao abandono, deixando os elementos da estação em estado de deterioração, como mostra a figura abaixo.

Figura 6. Situação atual da estação.

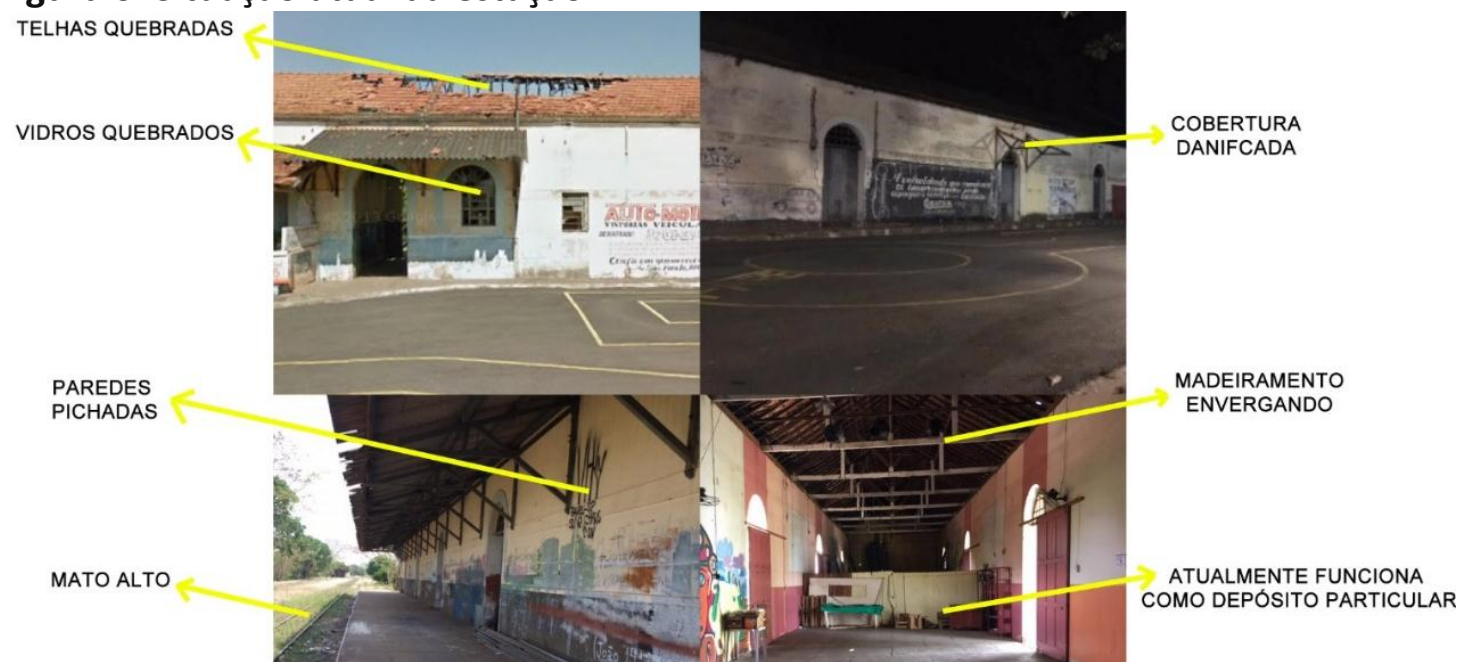

Fonte: Arquivo Pessoal, 2017

Entre os vários problemas causados pela falta de manutenção da estação ferroviária, o principal e que precisa passar pelo processo de intervenção com urgência corresponde à cobertura danificada, que em dias chuvosos, permite a entrada da chuva no interior do edifício, e com isso, acaba danificando todo o madeiramento da cobertura. Ainda dentro da edificação, encontra-se preservado e sem rachaduras o piso em concreto armado. Por 
possuir uma resistência maior, o material ainda encontra-se em um bom estado de conservação.

Diante do estado atual da edificação, é possível concluir que todo o contexto do complexo ferroviário precisa de intervenção, que proponha sua manutenção, preservação e por fim, a adaptação de um novo uso ao edifício. O edifício precisa ser restaurado, com o objetivo de manter sua autenticidade para que assim, não haja mais percas e danos quanto à memória social e coletiva.

\section{DISCUSSÃO}

É inadmissível que um setor que foi tão importante para o desenvolvimento econômico, social e tecnológico em nível nacional seja abandonado e esquecido, quando poderia ter sido restaurado e preservado para servir à população com uma nova função social. A edificação possui uma área significativa que pode ser voltada para a educação e ensino, exercendo a função de equipamento urbano cultural, tal como centro cultural.

\section{CONCLUSÃO}

Conclui-se que, por mais que o setor ferroviário não seja a opção mais viável para o transporte de cargas e pessoas atualmente, o mesmo já serviu o país e influenciou em grandes avanços em nível nacional. Os equipamentos ferroviários, responsáveis por influenciar na urbanização de muitas cidades, devem ser preservados em sua integridade e talvez receber um novo uso social voltado à população. $O$ objetivo da adaptação de um novo uso ao edifício é fazer com que a população enxergue, através de um centro de cultura e lazer, uma importância significativa e cheia de vida neste complexo arquitetônico industrial.

\section{REFERÊNCIAS}

FALLEIROS, A. Mirandópolis: sua evolução no século XX. São Paulo: Dom Bosco, s/a.

FARIA, S. O tempo não apaga: crônicas que retratam a história de Mirandópolis. 5. ed. Mirandópolis: s/e, s/a.

KUHL, B. Algumas questões relativas ao patrimônio industrial e à sua preservação. São Paulo: IPHAN, s/a.

KUHL, B. Patrimônio Industrial: algumas questões em aberto. São Paulo: USJT, 2010. 